\title{
Simulation training: a novel and effective way to improve knowledge and attitudes towards coroner"s court attendance
}

\author{
Kathryn M. 0'Shea, ${ }^{a, \star}$ Rachel Harwood, ${ }^{a}$ Joanna Crichton, ${ }^{b}$ Michelle Perrigo ${ }^{a}$ and Sarah Wood ${ }^{a}$ \\ ${ }^{a}$ Alder Hey Children's Hospital, Liverpool, L14 5AP, UK; ${ }^{b}$ Hill Dickinson, LLP, No. 1 St Paul's Square, Liverpool, L3 9SJ, UK \\ ${ }^{*}$ Corresponding author at: Alder Hey Children's Hospital, Department of Paediatric Surgery, East Prescot Road, Liverpool, L14 \\ 5AB, UK. Email: kathryn.m.oshea@gmail.com
}

Date accepted for publication: 31 August 2020

\section{Abstract}

Aim: Attending an inquest is almost inevitable during a surgeon's career. There is currently no requirement or provision for doctors in training to receive formal education regarding coroner's court. We aim to assess knowledge and attitudes towards the coroner's court process before and after attending a simulation-based training day. Methods: A paediatric surgery regional teaching day delivered interactive seminars on statement writing and the coroner's court, followed by a simulated inquest. A questionnaire assessing knowledge and attitudes was administered to all participants before and after attendance at the simulation day. Data were analysed using a chi-squared test. Significance levels were taken at $P<0.05$. Results: We report a 35/45 (78\%) pre-course response rate and a 28/47 (60\%) post-course response rate. Significant improvement in knowledge of the coroner's court process was reported in all areas questioned. The perception of the function of an inquest changed significantly after attending the course. The course did not significantly reduce the anticipated anxiety of health care professionals around the inquest process. Conclusion: We have demonstrated that simulation training improves knowledge and changes attitudes towards the coroner's court. However, it remains an anxiety-provoking experience and delivering a session on supporting the mental health of doctors would complement this well. We recommend that training on coroner's court and inquests becomes a mandated part of higher medical and surgical training and advise that simulation is an effective way of delivering this training.

Keywords: coroner's court; simulation training; knowledge and attitude

\section{Introduction}

In 2018, 220,600 deaths (41\% of all registered deaths) in England and Wales were reported to the coroner. Of these, $13 \%(29,100)$ were opened as coroner's court inquests in England and Wales. ${ }^{1}$ Our trust, a 270-bed tertiary children's hospital in the north west of England, has approximately 250,000 care episodes annually. There are around 50 deaths a year; 9 (2016), 11 (2017), 13 (2018) and 7 (as of May 2019 when our simulated inquest took place) were referred to the coroner. Having to attend coroner's court is almost inevitable for today's doctor. However, there is currently no requirement for doctors in training to receive formal education about this experience. There are private companies offering coroner's court training sessions, ${ }^{2,3}$ but these are few and far between and target specific groups, such as mental health teams or expert witnesses. To the best of our knowledge, there is currently no provision for coroner's court simulation to be delivered within higher medical or surgical training programmes. Being asked to attend coroner's court can be a highly stressful and anxious time for doctors. It entails preparing a statement, facing the family and being questioned about your part in the death of a patient. Doctors may feel their practice is being scrutinized, they may fear being found in the wrong, or they may fear having their professional standing questioned.

Prior knowledge of the process, a clear understanding of one's role, and being able to access appropriate support throughout are vital. Health Education England North West (HEENW) performed a self-assessment of doctors in training to establish knowledge of the support available surrounding the coroner's court process. This found 57\% of trainees had access to support from their clinical or educational supervisor if they were required to attend coroner's court. Thirty-three percent received support from their local department of education. Fifty-three percent had received some form of coroner's court training. No trainees were 
aware of the support that could be accessed via HEENW (A.P.J. Thomson, unpublished data relating to Coroner's Court reports and attendance in HEENW, personal communication, 2019). This survey highlights the variability in support and training, and a regionwide lack of uniform and robust systems for doctors in training faced with the prospect of attending a coroner's inquest.

Simulation has been shown to be an effective method of delivering teaching. ${ }^{4}$ It is commonplace in nursing and undergraduate medical education, and also many resident training programmes in the United States. Where it is used, it has been shown to improve both technical and non-technical skills, ${ }^{5}$ both of which are required when attending coroner's court. Simulation allows the re-creation of a real environment in a safe, controlled and supportive manner and is perfectly suited for learning about coroner's court in an experiential fashion.

We aimed to assess the knowledge and attitudes of health care professionals (within our region) towards the coroner's court process and to evaluate the effect of a simulation training day on knowledge and attitudes. To the best of our knowledge, this is the first study and intervention of its kind to be published in the medical literature.

\section{Methods}

The simulation training day was part of the regional teaching programme for paediatric surgical trainees. Attendance was opened up to nurses, paediatric trainees and consultants within the region. The course organizers and faculty consisted of a paediatric surgical consultant and registrar, two solicitors from the trust's legal team, a retired coroner from another region, and the trust's clinical legal services manager. A fictional case was prepared by the faculty with ward round documentation, observations, investigation reports, consent forms, theatre operation notes, and communications along with a full root cause analysis into the death.

Health care professionals were invited and allocated a role based on their profession, specialty and grade of training. Attendees were asked to review all the notes and to write a statement from the point of view of their allocated role. Some of the attendees received a formal simulated letter from the coroner calling them to attend as a witness of fact. An expert witness was also called to be present.

The programme for the course included an inquest simulation lasting 2-3 hours. This was complemented by two interactive knowledge-based sessions about the coroner's court and statement writing, using examples pre-agreed with several trainees from their statements. The hospital's
Schwartz ${ }^{6}$ team also presented a session centred around coroner's court titled 'A case you never forgot'.

The inquest simulation was held in a lecture room set to mirror a court room. The coroner, two solicitors, the 'mother' of the child and the court usher were present in the simulation. Witnesses were asked to swear an oath, the coroner questioned them, and allowed questions to be asked by the hospital and the family's legal representatives. The court heard evidence from the expert witness and a summary from the root cause analysis lead. The inquest then recessed until a conclusion (formerly known as a verdict) was made. The coroner summed up the evidence he had heard and delivered his conclusion. After the conclusion, a debrief was conducted about the process and the interactions, along with feelings, perceptions, worries, concerns and anything else that arose from participants.

Trainees were given feedback about statements from the faculty, and it was recommended that all trainees reviewed their statements formally, with their educational supervisors, with evidence added to their training portfolio.

A questionnaire was administered to all participants before attending the simulation day. The questionnaire comprised two sections: the first assessing knowledge pertaining to the coroner's court process and the second assessing attitudes towards the coroner's court process. The same questionnaire was sent out to participants after their attendance. Questions were focused primarily on personal feelings around different aspects of the courtroom process with response options of strongly agree, agree, neutral, disagree and strongly disagree. Agreement and disagreement are grouped within the results. Binary questions with a 'correct' answer requested a yes/no or true/false response.

\section{Statistical analysis}

Categorical data were analysed using a chi-squared test. Significance levels were taken at $P<0.05$.

\section{Results}

Forty-five pre-intervention questionnaires were circulated. There were 35 responses (78\% response rate). After the simulation training day, the questionnaire was circulated again to 47 participants; 28 responded $(60 \%$ response rate). There was no significant demographic difference between the pre- and post-intervention groups (Table 1). Four participants (11.4\%) had previously attended coroner's court training and $25 \%(n=9)$ had previous experience of attending coroner's court. One $(2.9 \%)$ had attended a coroner's court simulation previously. 
The analysis can be divided to assess participants' knowledge regarding the coroner's court process and their attitudes about coroner's court. Attendees of the course reported significant improvement in their knowledge of the coroner's court process across all areas questioned (Table 2). Regarding attitudes, there were significant improvements across many domains, including preparedness, familiarity and confidence. Interestingly, there was no statistically significant reduction in attendee's anxiety at the prospect of attending an inquest after the simulation training (Fig. 1).

One hundred percent of those surveyed would recommend this simulation training to others. Seventy-one percent of those asked felt that understanding coroner's court should be a mandatory part of the syllabus during higher surgical and medical training.

Table 1. Questionnaire respondents, displaying grade and specialty

\begin{tabular}{llll}
\hline Role & $\begin{array}{l}\text { Pre- } \\
\text { intervention }\end{array}$ & $\begin{array}{l}\text { Post- } \\
\text { intervention }\end{array}$ & $P$ \\
\hline Foundation/core trainee & 2 & 0 & 0.23 \\
Specialty trainee & 15 & 17 & \\
Consultant & 6 & 6 & \\
Nurse & 12 & 5 & \\
\hline
\end{tabular}

\section{Discussion}

The role of the coroner is summarized in Section 5 of the Coroner's and Justice Act 2009: 'The purpose of an investigation ... into a person's death is to ascertain - (a) who the deceased was; (b) how, when and where the deceased came by his death; (c) the particulars. ${ }^{7}$ The process is not designed to attribute blame or discredit doctors. However, these beliefs are common concerns held by doctors in relation to the coroner's court process.

Simulation-based education is as good as standard lecturebased teaching in delivering facts, with the additional benefit of encouraging a deeper learning that is far more likely to alter attitudes and practice. ${ }^{8}$ Our coroner's court simulation was designed with all learners in mind, by including visual, auditory and kinaesthetic opportunities available within the course. ${ }^{9}$ Taking into account all learning styles ensured we optimized learning across the diverse range of attendees taking a blended, whole-brain, learning approach. ${ }^{10}$ The course was designed to incorporate reflection within the simulation and encourage greater opportunity for meaningful learning. ${ }^{11}$

After the intervention, our results demonstrate a significant shift in attitude towards an inquest. Those surveyed felt more prepared, more confident in statement writing and more familiar with the process. Our results demonstrate the benefits of simulation in line with the literature ${ }^{12}$ and allow us to recommend this form of training.

\section{Pre and post course responses about attitudes to the Coroner's Court Process}

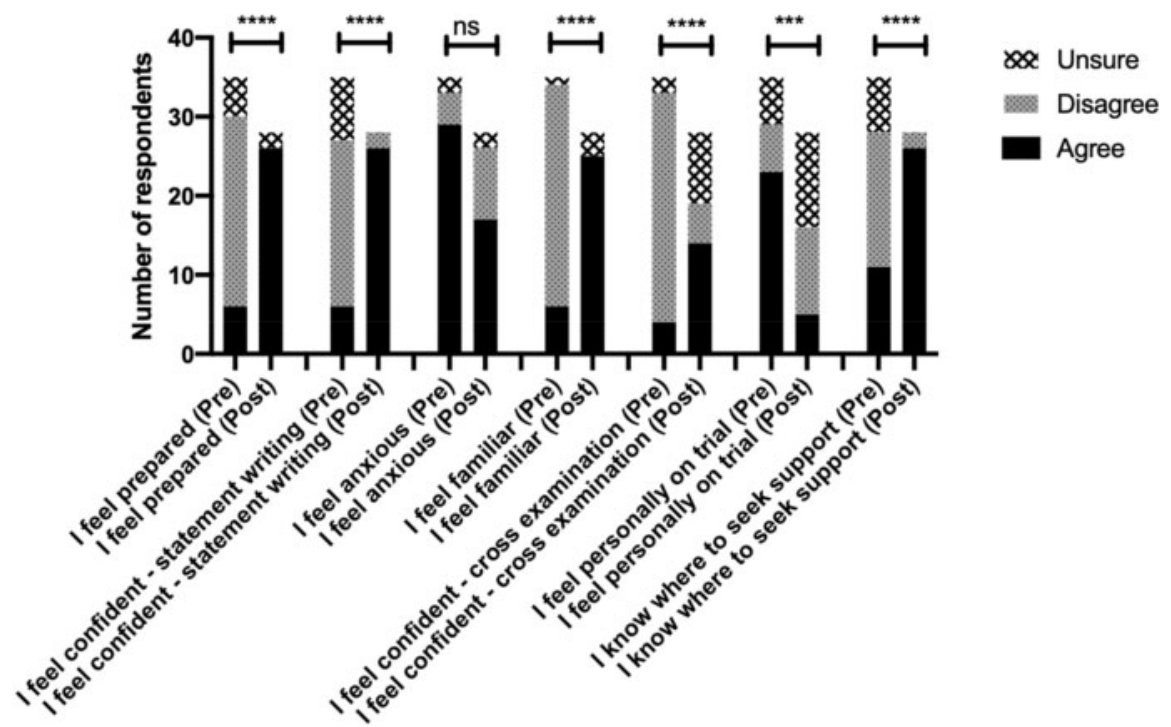

Figure 1. Pre- and post-course analysis of attitudes pertaining to the coroner's court process. 
Table 2. Pre- and post-course analysis of knowledge pertaining to the coroner's court process

\begin{tabular}{|c|c|c|c|c|c|c|c|}
\hline \multirow[t]{2}{*}{ Domain } & \multicolumn{3}{|c|}{ Pre-course $(n=35)$} & \multicolumn{3}{|c|}{ Post-course $(n=28)$} & \multirow[t]{2}{*}{$P$} \\
\hline & $\begin{array}{l}\text { Agree, } \\
n(\%)\end{array}$ & $\begin{array}{l}\text { Disagree, } \\
n(\%)\end{array}$ & $\begin{array}{l}\text { Neither, } \\
n(\%)\end{array}$ & $\begin{array}{l}\text { Agree, } \\
n(\%)\end{array}$ & $\begin{array}{l}\text { Disagree, } \\
n(\%)\end{array}$ & $\begin{array}{l}\text { Neither, } \\
n(\%)\end{array}$ & \\
\hline I know which deaths are reportable to the coroner & $17(49)$ & $12(34)$ & $6(17)$ & $27(96)$ & $0(0)$ & $1(4)$ & 0.0002 \\
\hline I know who will be present at coroner's court & $4(11)$ & $20(57)$ & $11(32)$ & $28(100)$ & $0(0)$ & $0(0)$ & $<0.0001$ \\
\hline I know what to expect during a cross-examination & $4(11)$ & $29(83)$ & $2(6)$ & $23(83)$ & $1(4)$ & $4(13)$ & $<0.0001$ \\
\hline The coroner's court process is a trial (true/false) & $9(26)$ & $26(74)$ & $0(0)$ & $0(0)$ & 28100 & $0(0)$ & 0.004 \\
\hline
\end{tabular}

The only area that did not demonstrate significant improvement was anxiety surrounding the coroner's court process. It has been found that objectively, simulation training improves performance, but subjective or personal assessment may contradict this. ${ }^{13}$ Perhaps, exposure to the situation leads participants to recognize anxieties they had not previously considered, or exposure makes them analyse themselves more deeply. Ultimately, it makes them feel less confident despite objective improvement. Qualitative research using semi-structured interviewing to enable further exploration of these anxieties would be of value. We also propose delivering a session on supporting the mental health of doctors. This combined approach may be successful in reducing anxiety relating to attending a coroner's court inquest. Furthermore, it is recognized that some degree of stress is beneficial for learning, but if a situation creates overwhelming anxiety, this can be detrimental to the learning environment. ${ }^{14}$ If someone with a high degree of anxiety regarding the coroner's court process took part in a simulation, this may reinforce their anxiety. Code and Burkard ${ }^{14}$ recommend ongoing debriefing as a strategy to deal with this. In future coroner's court simulations, small group debriefing could be utilized to help to reduce anxiety further. ${ }^{14}$

After the training day, $17 \%$ of participants still reported feeling they were personally on trial, despite reinforcement that the coroner's role is not to apportion blame. The similarities better known in a criminal court, such as standing in a dock, swearing an oath and testifying, are all things that popular culture has associated with an outcome of guilty or not guilty. Ongoing education may be required to realign beliefs.

There are several limitations to this study. We have used a before-and-after study design as opposed to study and control groups. This is a common approach within simulationbased education research. ${ }^{15}$ The validity of any study with a response rate less than $75 \%$ should be called into question. The post-course analysis had a response rate of $60 \%$. The low response rate could lead to selection bias, and this should be taken into account when interpreting the results. When further analysed, of the 19 non-responders, there were 11 consultants, six nurses and two junior doctors. The core target group for this training session was primarily paediatric surgical trainees; the response rate for this group was $100 \%$. Therefore, we feel that although the overall response rate is lower than desired, the data we have captured are for the core target group of trainees that this session is geared towards.

\section{Conclusion}

The process for education and support during training regarding coroner's court is inconsistent and unstandardized within our consortia, as demonstrated by a recent Health Education England questionnaire (A.J.P. Thomson, unpublished data relating to Coroner's Court reports and attendance in HEENW, personal communication, 2019). We expect that this pattern is reflected across the UK. We have demonstrated the benefits of simulation training in improving knowledge and changing attitudes towards the coroner's court. As an anxiety-provoking experience that is rare during training years, but much more common in consultancy, we recommend that training on coroner's court and inquests becomes a mandated part of higher medical and surgical training and advise that simulation is an effective way of delivering this training.

\section{Conflicts of interest}

None declared.

\section{References}

1. Ministry of Justice. Coroners statistics annual 2018 England and Wales. London: Ministry of Justice; 2019.

2. Bond Solon. Coroner's court training. Available from: https://www.bondsolon.com/courses/coroner's-court-training/. 
3. Maudsley Simulation. Coroners court inquest. 2017; Available from: https://www.maudsleysimulation.com/coroners-courtinquest.

4. Steadman RH, Coates WC, Huang YM, Matevosian R, Larmon BR, McCullough L, et al. Simulation-based training is superior to problem-based learning for the acquisition of critical assessment and management skills. Crit Care Med 2006; 34: 151-157. https://doi.org/10.1097/01.CCM.0000190 619.42013 .94 .

5. Palter VN, Grantcharov TP. Simulation in surgical education. CMAJ 2010; 182: 1191-1196. https://doi.org/10.1503/cmaj. 091743.

6. Schwartz Rounds. Available from: https://www.pointofcare foundation.org.uk/our-work/schwartz-rounds/.

7. Chambers DR. Medical evidence in the coroner's court. Med Sci Law 1985; 25: 103-107. https://doi.org/10.1177/0025802485 02500205.

8. Handfield-Jones R, Nasmith L, Steinert Y, Lawn N. Creativity in medical education: the use of innovative techniques in clinical teaching. Med Teach 1993; 15: 3-10. https://doi. org/10.3109/01421599309029005.

9. Anderson JA, Adams M. Acknowledging the learning styles of diverse student populations: Implications for instructional design. New Dir Teach Learn 1992; 49: 19-33. https://doi. org/10.1002/tl.37219924904.
10. Eagleton, S. Designing blended learning interventions for the 21st century student. Adv Physiol Educ 2017; 41: 203-211. https://doi.org/10.1152/advan.00149.2016.

11. Husebø SE, O’Regan S, Nestel D. Reflective practice and its role in simulation. Clin Simul Nurs 2015; 11: 368-375. https://doi.org/10.1016/j.ecns.2015.04.005.

12. Sørensen JL, Østergaard D, LeBlanc V, Ottesen B, Konge L, Dieckmann P, et al. Design of simulation-based medical education and advantages and disadvantages of in situ simulation versus off-site simulation. BMC Med Educ 2017; 17: 20. https://doi.org/10.1186/s12909-016-0838-3.

13. Ghoneim N, Dariya V, Guffey D, Minard CG, Frugé E, Harris LL, et al. Teaching NICU fellows how to relay difficult news using a simulation-based curriculum: does comfort lead to competence? Teach Learn Med 2019; 31: 207-221. https://doi.org/10.1080/10401334.2018.1490649.

14. Code ME, Burkard J. Too anxious to learn? Should the ongoing debriefing technique be amongst the best practices in simulation. J Anesth Crit Care 2016; 4: 00125. https://doi. org/10.15406/jaccoa.2016.04.00125.

15. Blackmore A, Kasfiki EV, Purva M. Simulation-based education to improve communication skills: a systematic review and identification of current best practice. BMJ Simul Technol Enhanc Learn 2018; 4: 159-164. http://dx.doi.org/10. 1136/bmjstel-2017-000220. 